\title{
Review Article \\ Genetics of Sub-Saharan African Human Population: Implications for HIV/AIDS, Tuberculosis, and Malaria
}

\author{
Gerald Mboowa ${ }^{1,2}$ \\ ${ }^{1}$ Department of Medical Microbiology, College of Health Sciences, Makerere University, P.O. Box 7072, Kampala, Uganda \\ ${ }^{2}$ School of Allied Health Sciences, International Health Sciences University, P.O. Box 7782, Kampala, Uganda
}

Correspondence should be addressed to Gerald Mboowa; gmboowa@yahoo.com

Received 28 April 2014; Revised 9 July 2014; Accepted 1 August 2014; Published 18 August 2014

Academic Editor: Yoko Satta

Copyright (C) 2014 Gerald Mboowa. This is an open access article distributed under the Creative Commons Attribution License, which permits unrestricted use, distribution, and reproduction in any medium, provided the original work is properly cited.

\begin{abstract}
Sub-Saharan Africa has continued leading in prevalence and incidence of major infectious disease killers such as HIV/AIDS, tuberculosis, and malaria. Epidemiological triad of infectious diseases includes susceptible host, pathogen, and environment. It is imperative that all aspects of vertices of the infectious disease triad are analysed to better understand why this is so. Studies done to address this intriguing reality though have mainly addressed pathogen and environmental components of the triad. Africa is the most genetically diverse region of the world as well as being the origin of modern humans. Malaria is relatively an ancient infection in this region as compared to TB and HIV/AIDS; from the evolutionary perspective, we would draw lessons that this ancestrally unique population now under three important infectious diseases both ancient and exotic will be skewed into increased genetic diversity; moreover, other evolutionary forces are also still at play. Host genetic diversity resulting from many years of malaria infection has been well documented in this population; we are yet to account for genetic diversity from the trio of these infections. Effect of host genetics on treatment outcome has been documented. Host genetics of sub-Saharan African population and its implication to infectious diseases are an important aspect that this review seeks to address.
\end{abstract}

\section{Introduction}

HIV/AIDS, TB, and malaria are three important killer diseases globally; however, these continue to devastate more of sub-Saharan African populations, with a total of 27 countries. Sub-Saharan Africa alone accounted for an estimated 70 percent of all people living with HIV [1] and 70 percent of all AIDS deaths in 2011 [2]. Data published by the World Health Organization (WHO 2014, http://www.who.int/mediacentre/factsheets/fs104/en/) indicate that sub-Saharan Africa carried the greatest proportion of new tuberculosis cases per population with over 255 cases per 100000 population in 2012. (WHO 2013 http://www.who.int/mediacentre/factsheets/fs094/en/) indicate most malaria cases and deaths occur in sub-Saharan Africa.

Sub-Saharan Africa is important regarding origin of human species and the way in which genetic variation affects human phenotypes. Africa is thought to be the ancestral homeland of all modern humans and is the most recent homeland of millions of individuals whose ancestors were brought to Europe and to the Americas as slaves [3]. There is much to be learned from the genetics of sub-Saharan African populations about human origins and evolution and about the origin and nature of human complex disease. At present, we have little understanding of the genetic structure of subSaharan populations and the genetic basis of complex disease in African populations because very few genetic studies have been conducted in African ethnic groups. Research activity has traditionally been biased towards the study of nonAfrican populations, and our knowledge of even the most fundamental information about the genetic basis of disease in Africa is quite limited [3] yet these three infectious diseases account for the highest morbidity and mortality. Increased funding and resources for studying genetic diversity in Africa are needed to reconstruct human evolutionary history, to dissect the genetic basis of resistance and susceptibility to disease, and to design better drugs for all people [3]. I suggest that this will require collaborative efforts with African institutions and ensure that the capacity is sustained. 
A shared set of DNA resources and the establishment of an African genetic database would help to provide researchers with common information and would facilitate studies of several loci in the same set of African populations. Studies also need to meet strict ethical standards and to involve both local researchers and study participants [3]. I am compelled to propose that modern humans who migrated away from sub-Saharan Africa encountered new environment and exotic pathogens in their new geographical niches. Those exotic pathogens and other evolutionary forces, which they met in the different areas where they settled, would account for unique genetics. Infectious diseases have continued and will continue shaping the course of human evolution.

The hypothesis whereby infectious diseases have been acting as a powerful selective pressure was formulated long ago, but it was not until the availability of large-scale genetic data and the development of novel methods to study molecular evolution that we could assess how pervasively infectious agents have shaped human genetic diversity [4]. Disease outcome is multifactorial process, requiring interplay of hostenvironment-microbial factors which ultimately determine disease resistance and progression. Genetic structures of the exposed human populations will determine the susceptibility patterns that are always observed in the host. Recent genomewide analysis indicates that among the diverse environmental factors that most likely acted as selective pressures during the evolution of human species (climate, diet regimes, and infections) pathogen load had the strongest influence on the shaping of human genetic variability [5]. Possibly the indigenous pathogens in sub-Saharan Africa coevolved with their hosts creating unique genetic profiles in these human populations. I propose that a form of Newton's third law of motion happens during an interaction between host and pathogen; action and reaction are equal and opposite. This implies that the selective pressure exerted by these pathogens onto selected host genes in response to specific pathogen genes received similar pressure from the host driving hostpathogen diversity observed as unique genetic profiles in both host and pathogen accounting for coevolution. Studies show certain host-pathogens specificities, probably due to coevolution. I further propose that these unique genetic profiles created over time affect vaccine efficacy and of late we know that treatment outcome is also affected by the host genetic structures. The unique genetic profiles created in these human populations can act as risk genetic factors for emerging pathogens. Penicillin was a wonder drug at the birth of the antibiotic era but after half a century of its clinical use, we observe emergence of penicillin resistant bacteria strains; these have acquired genetic variations that their ancestors never had. In the antibiotic/antiviral era, drugs are also likely to act as selective pressure creating genetic diversity in pathogen genomes as well as hosts'.

\section{Human Host Genetic Diversity and Infectious Diseases}

The high levels of genetic diversity in African populations and their demographic history make these populations particularly informative for the fine mapping of complex genetic diseases [6] as well as infectious diseases. Studies using mitochondrial (mt) DNA and nuclear DNA markers consistently indicate that Africa is the most genetically diverse region of the world [7]. Historically, human population genetic studies have relied on one or two African populations as being representative of African diversity, but recent studies show extensive genetic variation among even geographically close African populations, which indicates that there is not a single "representative" African population [3].

The immunological responses to MTB are due to the interaction between the immune system, human host, and bacterial and environmental factors [8]. Genetic as well as acquired defects in host immune response pathways greatly increase the risk of progressive disease [9]. Results from genome-wide linkage studies suggest that TB disease susceptibility is highly likely to be polygenic, with contributions from many minor loci [10], and a large number of TB susceptibility markers have been identified from candidate gene studies as "disease-causing" genes which include TIRAP, HLA DQB1, VDR, IL-12 $\beta$, IL12R $\beta 1$, IFN- $\gamma$, SLC11A1, and $\mathrm{MCP}-1$. However, to date the greatest evidence to support an underlying genetic basis for TB has come from the discovery of single gene defects predisposing to disseminated and often lethal mycobacterial disease [11].

To better understand why HIV/AIDS, tuberculosis, and malaria are more common infectious diseases in sub-Saharan Africa, we must appreciate the region's human genetic diversity and this will provide data that may help understand why there is a mixed population of both resistant and susceptible populations coexisting. We can assert that the indigenous infections like malaria and tuberculosis have created unique genetic structures in these mixed ethnic populations which can be risk factors for exotic infectious diseases like HIV/AIDS and vice versa. A notion that exposure to indigenous pathogens/parasites in these areas shaped the genetic structures of these native human populations resulting in interethnic variation in susceptibility to modern infectious agents is undisputable. The great human genetic diversity and the continued presence of infectious agents in sub-Saharan Africa will continue contributing to the observed susceptibilities to infectious diseases.

\section{HIV/AIDS}

Host genetic polymorphisms contribute to interindividual variation in susceptibility to acquiring HIV-1 infection, the degree of infectiousness to others (as reflected by the viral load), and rates of disease progression [12]. Such polymorphisms might also contribute to significant interpopulation differences in HIV-1 prevalence [12-16]. Duffy antigen receptor for chemokines (DARC) expressed on red blood cells (RBCs) influences plasma levels of HIV-1-suppressive and proinflammatory chemokines such as CCL5/RANTES [17]. DARC is also the RBC receptor for Plasmodium vivax. Africans with $D A R C-46 C / C$ genotype, which confers 
a DARC- negative phenotype, are resistant to vivax malaria. HIV-1 attaches to RBCs via DARC, effecting transinfection of target cells [17]. In African Americans, $D A R C-46 C / C$ is associated with $40 \%$ increase in the odds of acquiring HIV1 [17]. If extrapolated to Africans, about $11 \%$ of the HIV1 burden in Africa may be linked to this genotype. After infection occurs, however, DARC-negative RBC status is associated with slower disease progression [17].

Host genetic influence on HIV/AIDS susceptibility by a polymorphism that is differentially distributed between populations is best illustrated by the effects of the Europeanspecific 32 bp deletion (D32) in the gene for CC chemokine receptor 5 (CCR5), which is the major coreceptor for R5 strains of HIV-1 that represent the majority of transmissible viruses [18]. CCR5- $\Delta 32$ exhibit variable frequencies in distinct populations [19-22] and possibly their phenotypes depend on the host ethnicity analyzed [12, 20-24]. Distribution of the protective $\Delta 32$ allele is however restricted to Northern Europe, where it occurs at a frequency of (10-16)\% and its frequency decreases in a Southeast cline towards the Mediterranean and gradually disappears in the African and Asian populations [25]. The $\Delta 32$ mutation is most common in individuals of European descent but is absent or rare in the black African population [25]. A recent study in South Africa detected $\Delta 32$ mutation only in the Caucasian group and it also reported greater genetic diversity in CCR5 gene in the black South African population showing 39 mutations being exclusive [26]. This extensive variation in CCR5 gene in a small studied African population is in agreement with the concept that Africans have the greatest ethnic genetic diversity in the world.

The genes CCL3L1/CCL4L1 encode the chemokines MIP$1 \alpha$ and MIP-1 $\beta$ which are both ligands for the chemokine receptor CCR5 used as a coreceptor by $\mathrm{R} 5$ strains of HIV [27]. CCL3L1 gene dose has been associated with intersubject differences in susceptibility to HIV acquisition in European, African, and Hispanic-American adults, intravenous drug users from Estonia, and hemophiliacs from Japan $[13,28,29]$. The average copy number of CCL3L1 varies among populations [13]. A study in Central African Pygmies indicated that there might be a CCL3L1-CCR5dependent biological basis for interpopulation differences in HIV prevalence and concluded that the copy number of CCL3L1 genes is determinant of HIV-AIDS susceptibility [30].

The CCR5- $\Delta 32$ mutation along with single nucleotide polymorphisms (SNPs) in the CCR5 promoter and the CCR2-V64I mutation have been included in seven human haplogroups $(\mathrm{HH})$ previously associated with resistance/susceptibility to $\mathrm{HIV}-1$ infection and different rates of AIDS progression [31]. In vitro studies have demonstrated that HIV-1 can use alternative coreceptors, such as CCR2 [32]. A genetic variant of CCR2 (CCR2-V64I) leads to variations in the CCR2 transmembrane region and has been associated with slow progression to AIDS; however, its effect on susceptibility to acquire HIV-1 infection has not been defined to date [33]. This would be a study worth carrying out in sub-Saharan African population. Recently, the immunoregulatory cytokine IL-10 was identified as playing a key role in suppressing antiviral immune responses, leading to viral persistence $[34,35]$. A study in South Africa populations indicated that individuals carrying the IL-10592AA genotype were more likely to become HIV-1 infected further; these results generally suggested that IL-10 promoter polymorphisms were linked to low IL-10 production and associated with increased HIV-1 susceptibility [36].

A study in Kenya revealed pathological interactions between HIV and malaria in dually infected patients, but the public health implications of the interplay have remained unclear [37]. A transient almost one-log elevation in HIV viral load occurred during febrile malaria episodes; in addition, susceptibility to malaria was enhanced in HIVinfected patients [37]. Coinfection might also have facilitated the geographic expansion of malaria in areas where HIV prevalence is high; therefore, transient and repeated increases in HIV viral load resulting from recurrent coinfection with malaria may be an important factor in promoting the spread of HIV in sub-Saharan Africa [37].

\section{Tuberculosis}

A lot of attention has been given to study the importance of the Mycobacterium tuberculosis pathogen and the genetic constitution of the host largely ignored especially in the most affected regions like sub-Saharan Africa. It is estimated that only $10 \%$ of those who become infected with Mycobacterium tuberculosis will ever develop clinical disease [38]. A growing body of evidence suggests that host genetics play a role in the predisposition to tuberculosis (TB) disease, in addition to pathogen, environmental, and socioeconomic factors [39, 40]. Genetic factors contributing to TB susceptibility include variants of the human leukocyte antigen (HLA) class II complex [41-44] and the vitamin D receptor gene (VDR) [4548]. HLA alleles are found to be associated with susceptibility and resistance to infectious diseases including HIV/AIDS, tuberculosis, and malaria that impose huge public health burdens in sub-Saharan Africa $[49,50]$. HLA studies have also yielded important insights into the role of pathogens in driving HLA polymorphism. For example, a study that analyzed 61 human populations across the world showed that populations that have a greater burden of pathogens show higher HLA diversity and those populations farther from Africa (geographic distance measured through landmasses from Ethiopia) are characterized by lower HLA diversity [51].

Tuberculosis was a major selective force in the evolution of Western European populations, whereas malaria served a similar role in Africa [52, 53]. Genes involved in protective immunity are under greater selective pressure, showing greater variability than other genes $[52,53]$. For a disease to be a selective pressure in the evolution of a human population, the gene would have to have a significant impact for long periods of time, influencing morbidity and mortality before reproductive age $[52,53]$. TB is currently a world-wide pathogen, and archeologic evidence indicates a great prehistoric prevalence for the disease in crowded cities of Europe and North Africa [54, 55]. It appears, however, that this organism was once completely absent from several isolated 
areas [56, 57], the largest of which was Africa [58]. Recent observations strongly suggest a significant role for genetic factors in innate resistance to infection by Mycobacterium tuberculosis [58]. This relation was discovered in a study of tuberculosis in Arkansas nursing homes and was supported by data from three outbreaks of tuberculosis in two prisons [58]. A person's resistance level was found to correlate with the region of his or her ancestry [58]. Ancestors of persons in the more resistant group tended to derive from densely populated areas and cities rife with tuberculosis, whereas the ancestors of persons in the more susceptible group tended to derive from areas once free of tuberculosis [58].

With the completion of Human Genome Project and advances in genotyping technology, Genome-Wide Association (GWA) Study has been one powerful tool for the study of genetic susceptibility in human complex diseases [59]. Recently a study conducted in Ghana and The Gambia using Genome-Wide Association Study (GWAS) identified a susceptibility locus of rs4331426 on chromosome 18q11.2 for tuberculosis in the African population [60]. In a case-control study in The Gambia, two candidate genes, natural resistance associated macrophage protein (NRAMP1) and VDR, were found to be associated with tuberculosis [46, 61]. Another study in The Gambia and South Africa reported using a genome-wide search on a large number of families with an infectious disease results from linkage analysis alone provided suggestive evidence for tuberculosis-susceptibility genes on chromosomes $15 \mathrm{q}$ and $\mathrm{Xq}$, and these results were supported by the results of common ancestry using microsatellite (CAM) mapping [62].

Macrophage migration inhibitory factor (MIF) is an innate cytokine encoded in a functionally polymorphic genetic locus [63]. The number of CATT tetranucleotide repeats at -794 is associated with differential MIF expression: the -794 CATT5 variant is a low-expression allele [63]. Globally, the CATT5 allele is more frequently identified among African-Americans and Africans compared with their Caucasian American or Western European counterparts [64]. The proposed MIF-TB susceptibility allele (-794 CATT5) is found commonly in Caucasians $(\sim 45 \%)$ and is more prevalent in African-Americans and in Africans (60$80 \%$ ), indicating that MIF genotype may make a clinically meaningful contribution to TB disease risk $[64,65]$. The results from a recent study in Uganda found that mycobacteremic subjects were more likely to be genotypic low expressers of MIF (-794 CATT5/5, 33\% versus $18 \%$, odds ratio $(\mathrm{OR}) 2.2, P=0.009)$. This association remained significant in multivariate analysis adjusting for age, sex, CD4 count, and use of highly active antiretroviral therapy (HAART) [63].

Studies by Khor et al., looking at variant alleles of CISH gene polymorphisms and susceptibility to infectious diseases found that the minor alleles of three SNPs $(-292,+1320$, and +3415 ) were associated with increased susceptibility to TB in Malawian population and further reported that TB susceptibility in the Gambia was accounted for by more than one SNP, implying a highly genetically diverse population [66].

\section{Malaria}

During the course of human evolution in regions where malaria is prevalent, naturally occurring genetic defense mechanisms have evolved for resisting infection by plasmodium [67]. Most of the human genes that are thought to provide reduced risk from malarial infection are expressed in red blood cells or play a role in the immune system and they include human leukocyte antigen (HLA), $\alpha$ - and $\beta$ globin, Duffy factor (FY), tumor necrosis factor (TNF), $\alpha$ and glucose-6-phosphate dehydrogenase (G6PD) [67]. Perhaps no disease in history has exerted as strong a selective pressure on the human genome as falciparum malaria [67]. Evidence suggests that Plasmodium falciparum has infected humans for at least 5000-10,000 years, and human haplotype studies have shown that alleles that may offer protection against malaria have undergone selection during that same time frame [68, 69]. The selection pressure from malaria has led to many variants of erythrocytes other than hemoglobin S (HbS) [70].

Anatomically modern humans appeared in East Africa about 200,000 years ago, spread out from sub-Saharan Africa approximately 100,000 years ago, and subsequently colonized the rest of the world in a series of migratory events [71]. This implies that ethnic populations that remained in subSaharan Africa have been exposed to malaria for periods long enough to shape their genetic structures by plasmodium unlike those that left this region around that time. Geographical, epidemiological, and in vitro evidence support the hypothesis that G6PD enzyme deficiency confers protection from disease caused by the Plasmodium falciparum parasite [72]. G6PD is encoded by a $16.2 \mathrm{~kb}$ gene found on the $\mathrm{X}$ chromosome and approximately 160 genetic variants causing clinical deficiency of G6PD have been characterized [73]. The geographical distribution of these deficiency alleles closely reflects human populations exposed historically to endemic malaria [74]. Relatively little attention has been given to the associations between genetic polymorphisms and uncomplicated malaria, which accounts for over $99 \%$ of malarial illnesses in countries where malaria is endemic [75]. The 202A/376G G6PD A-allele is considered to be the most common G6PD deficiency allele in sub-Saharan Africa [76], though incidence and prevalence of malaria have continued to be high in this region yet known to confer protection against malaria. We suggest that protection may be conferred by more than one gene; concept remains to be elucidated.

In western and central Africa, $95 \%-99 \%$ of humans have the Duffy negative phenotype, a condition that is thought to confer complete protection against the Plasmodium vivax during the blood stages of its life cycle [77, 78]; however, Plasmodium falciparum is known to be the commonest cause of malaria in Africa making this phenotype less useful in sub-Saharan African population. A study on human genetic polymorphisms and asymptomatic Plasmodium falciparum malaria in Gabonese school children did not find statistically significant association between mannose binding lectin (MBL), tumor necrosis factor- $\alpha$ (TNF- $\alpha$ ), and nitric oxide synthase 2(NOS2) polymorphisms and asymptomatic malaria [79]. Reports associating several genetic disorders with malaria susceptibility or resistance are on the rise, and 
studies of heritability indicate that approximately $25 \%$ of the risk for severe malaria progression is determined through human genetic factors [80]. The genetic background of the affected individual might also influence cytokine expression and disease outcomes [81, 82]. Notably, the frequency of genetic alterations differs depending on the population origin and structure, and some mutations might differentially influence the disease outcome in different patterns [80]. However, heritability studies have suggested that although about $25 \%$ of total variation in malaria incidence and hospitalization can be accounted for by host genetic variation, sickle cell status accounts for only $2 \%$ of this variation [83]. Thus, many other genetic factors likely affect the outcome studied by Crompton et al. [83]. Moreover, specific genetic factors will likely affect different populations differently, and certain polymorphisms (e.g., absence of the Duffy antigen, which protects against Plasmodium vivax infection primarily in Africans, and the band 3 mutation that causes ovalocytosis, primarily in Asian populations) have strong geographic determinants [68].

\section{Concluding Remarks}

Infectious diseases continue to present a major threat for human populations and, consequently, shape genetic diversity of human populations. In the western world, application of genetic and genomic technologies to study human genetic basis of diseases has been widely performed; however, in sub-Saharan Africa, where infectious diseases remain an important component of human survival, these studies are limited in sub-Saharan Africa. A lot of research has been done to describe pathogen and environment factors associated with the high prevalence and incidence of these diseases in sub-Saharan Africa; however, less attention has been given to human host genetic factors in sub-Saharan Africa population largely due to limited expertise in Africa scholars and the technologies. This has been further complicated by the fact that more than $40 \%$ of African scientists live in Organization for Economic Cooperation and Development (OECD) countries, predominately in Europe, the United States, and Canada [83]. In some OECD countries, like the United States, sub-Saharan Africans are the most educated immigrant group [84]. Therefore, African institutions should embrace genetic and genomic studies so that they can provide meaningful data on the genetic basis of infectious diseases in sub-Saharan Africa human population. This will guide new drug and vaccine development. This will increase our understanding of the human genetic markers responsible for the observed variations in susceptibilities to infectious diseases in human populations in sub-Saharan Africa.

Genetics can affect treatment outcomes, as was demonstrated in a recent study that showed sulfadoxinepyrimethamine treatment to be approximately half as likely to fail in children with sickle cell trait, compared with children who had normal hemoglobin [85]. This further may require that regions embrace individualized medicines, since even in the proantibiotic/proantiviral and vaccine era, no much significant success has been registered to eliminate these infectious diseases. Host genetic diversity in this region may need to be matched with customized medicines. This will need collaborations and commitment from Africans at various levels. We are optimistic that genetic and genomic studies on large sub-Saharan African population will provide a great deal of insight into why the three important global infectious diseases are more prevalent in this region irrespective of available interventions and further guide new treatment interventions and vaccine development.

\section{Conflict of Interests}

The author declares that there is no conflict of interests regarding the publication of this paper.

\section{References}

[1] Global Fact Sheet, Joint United Nations Programme on HIV and AIDS, 20 November 2012.

[2] UNAIDS Report on the Global AIDS Epidemic 2012.

[3] S. A. Tishkoff and S. M. Williams, "Genetic analysis of African populations: Human evolution and complex disease," Nature Reviews Genetics, vol. 3, no. 8, pp. 611-621, 2002.

[4] R. Cagliani and M. Sironi, "Pathogen-driven selection in the human genome," International Journal of Evolutionary Biology, vol. 10, pp. 1155-1161, 2013.

[5] M. Fumagalli, M. Sironi, U. Pozzoli, A. Ferrer-Admettla, L. Pattini, and R. Nielsen, "Signatures of environmental genetic adaptation pinpoint pathogens as the main selective pressure through human evolution," PLoS Genetics, vol. 7, no. 11, Article ID e1002355, 2011.

[6] L. B. Jorde, W. S. Watkins, and M. J. Bamshad, "Population genomics: a bridge from evolutionary history to genetic medicine," Human Molecular Genetics, vol. 10, no. 20, pp. 21992207, 2001.

[7] L. B. Jorde, W. S. Watkins, M. J. Bamshad et al., "The distribution of human genetic diversity: a comparison of mitochondrial, autosomal, and Y-chromosome data," The American Journal of Human Genetics, vol. 66, no. 3, pp. 979-988, 2000.

[8] D. B. Meya and K. P. W. J. McAdam, "The TB pandemic: an old problem seeking new solutions," Journal of Internal Medicine, vol. 261, no. 4, pp. 309-329, 2007.

[9] B. Kampmann, C. Hemingway, A. Stephens et al., "Acquired predisposition to mycobacterial disease due to autoantibodies to IFN- $\gamma$," Journal of Clinical Investigation, vol. 115, no. 9, pp. 2480-2488, 2005.

[10] P. C. Hill, R. H. Brookes, I. M. O. Adetifa et al., "Comparison of enzyme-linked immunospot assay and tuberculin skin test in healthy children exposed to Mycobacterium tuberculosis," Pediatrics, vol. 117, no. 5, pp. 1542-1548, 2006.

[11] S. M. Newton, A. J. Brent, S. Anderson, E. Whittaker, and B. Kampmann, "Paediatric tuberculosis," The Lancet Infectious Diseases, vol. 8, no. 8, pp. 498-510, 2008.

[12] E. Gonzalez, M. Bamshad, N. M. Sato et al., "Race-specific HIV1 disease-modifying effects associated with CCR5 haplotypes," Proceedings of the National Academy of Sciences of the United States of America, vol. 96, no. 21, pp. 12004-12009, 1999.

[13] E. Gonzalez, H. Kulkarni, H. Bolivar et al., "The influence of CCL3L1 gene-containing segmental duplications on HIV1/AIDS susceptibility," Science, vol. 307, no. 5714, pp. 1434-1440, 2005. 
[14] P. Schliekelman, C. Garner, and M. Slatkin, "Natural selection and resistance to HIV," Nature, vol. 411, no. 6837, pp. 545-546, 2001.

[15] A. D. Sullivan, J. Wigginton, and D. Kirschner, "The coreceptor mutation CCR 532 influences the dynamics of hiv epidemics and is selected for by HIV," Proceedings of the National Academy of Sciences of the United States of America, vol. 98, no. 18, pp. 10214-10219, 2001.

[16] C. Winkler, P. An, and S. J. O'Brien, "Patterns of ethnic diversity among the genes that influence AIDS," Human Molecular Genetics, vol. 13, no. 1, pp. 9-19, 2004.

[17] W. He, S. Neil, H. Kulkarni et al., "Duffy Antigen Receptor for Chemokines Mediates trans-Infection of HIV-1 from Red Blood Cells to Target Cells and Affects HIV-AIDS Susceptibility," Cell Host and Microbe, vol. 4, no. 1, pp. 52-62, 2008.

[18] J. Lama and V. Planelles, "Host factors influencing susceptibility to HIV infection and AIDS progression," Retrovirology, vol. 4, article 52, 2007.

[19] A. H. Salem, E. Farid, R. Fadel et al., "Distribution of four HIV type 1-resistance polymorphisms (CCR5- $\Delta 32$, CCR5-m303, CCR2-64I, and SDF1-3'A) in the Bahraini population," AIDS Research and Human Retroviruses, vol. 25, no. 10, pp. 973-977, 2009.

[20] E. Gonzalez, R. Dhanda, M. Bamshad et al., "Global survey of genetic variation in CCR5, RANTES, and MIP-1 $\alpha$ : impact on the epidemiology of the HIV-1 pandemic," Proceedings of the National Academy of Sciences of the United States of America, vol. 98, no. 9, pp. 5199-5204, 2001.

[21] B. Su, G. Sun, D. Lu et al., "Distribution of three HIV-1 resistance-conferring polymorphisms (SDF1-3'A, CCR2-641, and CCR5- $\triangle 32$ ) in global populations," European Journal of Human Genetics, vol. 8, no. 12, pp. 975-979, 2000.

[22] M. W. Smith, M. Dean, M. Carrington et al., "Contrasting genetic influence of CCR2 and CCR5 variants on HIV-1 infection and disease progression. Hemophilia growth and development study (HGDS), multicenter AIDS cohort study (MACS), multicenter hemophilia cohort study (MHCS), San Francisco City Cohort (SFCC), ALIVE study," Science, vol. 277, pp. 959-965, 1997.

[23] S. Mummidi, S. S. Ahuja, E. Gonzalez et al., "Genealogy of the CCR5 locus and chemokine system gene variants associated with altered rates of HIV-1 disease progression," Nature Medicine, vol. 4, no. 7, pp. 786-793, 1998.

[24] P. An, M. P. Martin, G. W. Nelson et al., "Influence of CCR5 promoter haplotypes on AIDS progression in African-Americans," AIDS, vol. 14, no. 14, pp. 2117-2122, 2000.

[25] J. J. Martinson, N. H. Chapman, D. C. Rees, Y. T. Liu, and J. B. Clegg, "Global distribution of the CCR5 gene 32-basepair deletion," Nature Genetics, vol. 16, no. 1, pp. 100-103, 1997.

[26] F. Barmania, M. Potgieter, and M. S. Pepper, "Mutations in C-C chemokine receptor type 5 (CCR5) in South African individuals," International Journal of Infectious Diseases, vol. 17, no. 12, pp. el148-e1153, 2013.

[27] E. Aklillu, L. Odenthal-Hesse, J. Bowdrey et al., "CCL3L1 copy number, HIV load, and immune reconstitution in sub-Saharan Africans," BMC Infectious Diseases, vol. 13, article 536, 2013.

[28] M. Sadam, T. Karki, K. Huik et al., "CCL3L1 variable gene copy number influence on the susceptibility to HIV-1/AIDS among estonian intravenous drug user," in Proceedings of the 15th Conference on Retroviruses and Opportunistic Infections (CROI '08), Abstract 296, 2008.
[29] T. Nakajima, H. Ohtani, T. Naruse et al., "Copy number variations of CCL $3 L 1$ and long-term prognosis of HIV-1 infection in asymptomatic HIV-infected Japanese with hemophilia," Immunogenetics, vol. 59, no. 10, pp. 793-798, 2007.

[30] H. Kulkarni, V. C. Marconi, B. K. Agan et al., "Role of CCL3L1-CCR5 genotypes in the epidemic spread of HIV-1 and evaluation of vaccine efficacy," PLoS ONE, vol. 3, no. 11, Article ID e3671, 2008.

[31] W. Zapata, W. Aguilar-Jiménez, N. Pineda-Trujillo, W. Rojas, H. Estrada, and M. T. Rugeles, "Influence of CCR5 and CCR2 genetic variants in the resistance/susceptibility to HIV in serodiscordant couples from Colombia," AIDS Research and Human Retroviruses, vol. 29, no. 12, pp. 1594-1603, 2013.

[32] B. Lee, B. J. Doranz, S. Rana et al., "Influence of the CCR2V64I polymorphism on human immunodeficiency virus type 1 coreceptor activity and on chemokine receptor function of CCR2b, CCR3, CCR5, and CXCR4," Journal of Virology, vol. 72, no. 9, pp. 7450-7458, 1998.

[33] S. Mummidi, M. Bamshad, S. S. Ahuja et al., "Evolution of human and non-human primate CC chemokine receptor 5 gene and mRNA: Potential roles for haplotype and mRNA diversity, differential haplotype-specific transcriptional activity, and altered transcription factor binding to polymorphic nucleotides in the pathogenesis of HIV-1 and simian immunodeficiency virus," Journal of Biological Chemistry, vol. 275, no. 25, pp. 18946-18961, 2000.

[34] D. G. Brooks, M. J. Trifilo, K. H. Edelmann, L. Teyton, D. B. McGavern, and M. B. A. Oldstone, "Interleukin-10 determines viral clearance or persistence in vivo," Nature Medicine, vol. 12, no. 11, pp. 1301-1309, 2006.

[35] M. Ejrnaes, C. M. Filippi, M. M. Martinic et al., "Resolution of a chronic viral infection after interleukin-10 receptor blockade," The Journal of Experimental Medicine, vol. 203, no. 11, pp. 24612472, 2006.

[36] D. D. Naicker, L. Werner, E. Kormuth et al., "Interleukin-10 promoter polymorphisms influence HIV-1 susceptibility and primary HIV-1 pathogenesis," Journal of Infectious Diseases, vol. 200, no. 3, pp. 448-452, 2009.

[37] L. J. Abu-Raddad, P. Patnaik, and J. G. Kublin, "Dual infection with HIV and malaria fuels the spread of both diseases in SubSaharan Africa," Science, vol. 314, no. 5805, pp. 1603-1606, 2006.

[38] C. J. L. Murray, K. Styblo, and A. Rouillon, "Tuberculosis in developing countries: Burden, intervention and cost," Bulletin of the International Union Against Tuberculosis and Lung Disease, vol. 65, no. 1, pp. 6-24, 1990.

[39] G. S. Cooke and M. R. Siddiqui, "Host genetics and the dissection of mycobacterial immunity," Clinical and Experimental Immunology, vol. 135, no. 1, pp. 9-11, 2004.

[40] H. McShane, "Susceptibility to tuberculosis-the importance of the pathogen as well as the host," Clinical and Experimental Immunology, vol. 133, no. 1, pp. 20-21, 2003.

[41] P. Selvaraj, H. Uma, A. M. Reetha et al., "HLA antigen profile in pulmonary tuberculosis patients and their spouses," Indian Journal of Medical Research, vol. 107, pp. 155-158, 1998.

[42] M. Ravikumar, V. Dheenadhayalan, K. Rajaram et al., "Associations of HLA-DRB1, DQB1 and DPB1 alleles with pulmonary tuberculosis in south India," Tubercle and Lung Disease, vol. 79, no. 5, pp. 309-317, 1999.

[43] A. Dubaniewicz, B. Lewko, G. Moszkowska, B. Zamorska, and J. Stepinski, "Molecular subtypes of the HLA-DR antigens in pulmonary tuberculosis," International Journal of Infectious Diseases, vol. 4, no. 3, pp. 129-133, 2000. 
[44] A. E. Goldfeld, J. C. Delgado, S. Thim et al., "Association of an HLA-DQ allele with clinical tuberculosis," Journal of the American Medical Association, vol. 279, no. 3, pp. 226-228, 1998.

[45] L. Bornman, S. J. Campbell, K. Fielding et al., "Vitamin D receptor polymorphisms and susceptibility to tuberculosis in West Africa: a case-control and family study," Journal of Infectious Diseases, vol. 190, no. 9, pp. 1631-1641, 2004.

[46] R. Bellamy, C. Ruwende, T. Corrah et al., "Tuberculosis and chronic hepatitis B virus infection in Africans and variation in the vitamin D receptor gene," Journal of Infectious Diseases, vol. 179, no. 3, pp. 721-724, 1999.

[47] R. J. Wilkinson, M. Llewelyn, Z. Toossi et al., "Influence of vitamin $\mathrm{D}$ deficiency and vitamin $\mathrm{D}$ receptor polymorphisms on tuberculosis among Gujarati Asians in west London: a casecontrol study," The Lancet, vol. 355, no. 9204, pp. 618-621, 2000.

[48] P. Selvaraj, P. R. Narayanan, and A. M. Reetha, "Association of vitamin D receptor genotypes with the susceptibility to pulmonary tuberculosis in female patients and resistance in female contacts," Indian Journal of Medical Research, vol. 111, pp. 172-179, 2000.

[49] J. M. Blackwell, S. E. Jamieson, and D. Burgner, "HLA and infectious diseases," Clinical Microbiology Reviews, vol. 22, no. 2, pp. 370-385, 2009.

[50] The Global Burden of Disease: 2004 Update, World Health Organization, Geneva, Switzerland, 2008, http://www.who.int/healthinfo/global_burden_disease/GBD_ report_2004update_AnnexA.pdf.

[51] F. Prugnolle, A. Manica, M. Charpentier, J. F. Guégan, V. Guernier, and F. Balloux, "Pathogen-driven selection and worldwide HLA class I diversity," Current Biology, vol. 15, no. 11, pp. 1022-1027, 2005.

[52] L. H. Miller, "Impact of malaria on genetic polymorphism and genetic diseases in Africans and African Americans," Proceedings of the National Academy of Sciences of the United States of America, vol. 91, no. 7, pp. 2415-2419, 1994.

[53] G. S. Cooke and A. V. S. Hill, "Genetics of susceptibility to human infectious disease," Nature Reviews Genetics, vol. 2, no. 12, pp. 967-977, 2001.

[54] M. D. Grmek, Diseases in the Ancient Greek World, Johns Hopkins Press, Baltimore, Md, USA, 1989.

[55] D. Brothweii and A. T. Sandison, Diseases in Antiquity-A Survey of the Diseases, Injuries and Surgery of Early Populations, Charles Thomas, Springfield, Ill, USA, 1967.

[56] G. E. Bushnell, A Study of the Epidemiology of Tuberculosis, with Especial Reference to Tuberculosis of the Tropics and of the Negro Race, William Wood \& Co, New York, NY, USA, 1920.

[57] N. Nuteis, Medical Problems of Newly Contacted Indian Group, vol. 165, Pan American Health Organization, Scientific Publications, Washington, DC, USA, 1968.

[58] W. W. Stead, "Genetics and resistance to tuberculosis: could resistance be enhanced by genetic engineering " Annals of Internal Medicine, vol. 116, no. 11, pp. 937-941, 1992.

[59] T. Wang and H. Wang, "A genome-wide association study primer for clinicians," Taiwanese Journal of Obstetrics and Gynecology, vol. 48, no. 2, pp. 89-95, 2009.

[60] R. Bellamy, C. Ruwende, T. Corrah, K. P. W. J. McAdam, H. C. Whittle, and A. V. S. Hill, "Variations in the NRAMP1 gene and susceptibility to tuberculosis in West Africans," The New England Journal of Medicine, vol. 338, no. 10, pp. 640-644, 1998.

[61] R. Bellamy, N. Beyers, K. P. W. J. McAdam et al., "Genetic susceptibility to tuberculosis in Africans: a genome-wide scan,"
Proceedings of the National Academy of Sciences of the United States of America, vol. 97, no. 14, pp. 8005-8009, 2000.

[62] R. Das, M. S. Koo, B. H. Kim et al., "Macrophage migration inhibitory factor (MIF) is a critical mediator of the innate immune response to Mycobacterium tuberculosis," Proceedings of the National Academy of Sciences of the United States of America, vol. 110, no. 32, pp. e2997-e3006, 2013.

[63] W. W. Stead, J. W. Senner, W. T. Reddick, and J. P. Lofgren, "Racial differences in susceptibility to infection by Mycobacterium tuberculosis," The New England Journal of Medicine, vol. 322, no. 7, pp. 422-427, 1990.

[64] X. Zhong, L. Leng, A. Beitin et al., "Simultaneous detection of microsatellite repeats and SNPs in the macrophage migration inhibitory factor (MIF) gene by thin-film biosensor chips and application to rural field studies.", Nucleic Acids Research, vol. 33, no. 13, pp. el21-e137, 2005.

[65] S. A. Tishkoff, R. Varkonyi, N. Cahinhinan et al., "Haplotype diversity and linkage disequilibrium at human G6PD: recent origin of alleles that confer malarial resistance," Science, vol. 293, no. 5529, pp. 455-462, 2001.

[66] C. C. Khor, F. O. Vannberg, S. J. Chapman et al., "CISH and susceptibility to infectious diseases," The New England Journal of Medicine, vol. 362, pp. 22-32, 2010.

[67] S. Parikh and P. J. Rosenthal, "Human genetics and malaria: relevance for the design of clinical trials," Journal of Infectious Diseases, vol. 198, no. 9, pp. 1255-1257, 2008.

[68] P. C. Sabeti, D. E. Reich, J. M. Higgins et al., "Detecting recent positive selection in the human genome from haplotype structure," Nature, vol. 419, no. 6909, pp. 832-837, 2002.

[69] D. L. Hartl, "The origin of malaria: mixed messages from genetic diversity," Nature Reviews Microbiology, vol. 2, no. 1, pp. 15-22, 2004.

[70] J. Ohashi, I. Naka, J. Patarapotikul et al., "Extended linkage disequilibrium surrounding the hemoglobin $\mathrm{E}$ variant due to malarial selection," The American Journal of Human Genetics, vol. 74, no. 6, pp. 1198-1208, 2004.

[71] T. D. White, B. Asfaw, D. DeGusta et al., "Pleistocene Homo sapiens from Middle Awash, Ethiopia," Nature, vol. 423, no. 6941, pp. 742-747, 2003.

[72] C. Ruwende and A. Hill, "Glucose-6-phosphate dehydrogenase deficiency and malaria," Journal of Molecular Medicine, vol. 76, no. 8, pp. 581-588, 1998.

[73] P. J. Mason, J. M. Bautista, and F. Gilsanz, "G6PD deficiency: the genotype-phenotype association," Blood Reviews, vol. 21, no. 5, pp. 267-283, 2007.

[74] A. C. Allison and D. F. Clyde, "Malaria in African children with deficient erythrocyte glucose-6-phosphate dehydrogenase.," British Medical Journal, vol. 1, no. 5236, pp. 1346-1349, 1961.

[75] R. W. Snow, C. A. Guerra, A. M. Noor, H. Y. Myint, and S. I. Hay, "The global distribution of clinical episodes of Plasmodium falciparum malaria," Nature, vol. 434, no. 7030, pp. 214-217, 2005.

[76] T. G. Clark, A. E. Fry, S. Auburn et al., "Allelic heterogeneity of G6PD deficiency in West Africa and severe malaria susceptibility," European Journal of Human Genetics, vol. 17, no. 8, pp. 1080-1085, 2009.

[77] L. H. Miller, S. J. Mason, D. F. Clyde, and M. H. McGinniss, "The resistance factor to Plasmodium vivax in blacks. The Duffy blood group genotype, FyFy," The New England Journal of Medicine, vol. 295, no. 6, pp. 302-304, 1976. 
[78] R. L. Culleton, T. Mita, M. Ndounga et al., "Failure to detect Plasmodium vivax in West and Central Africa by PCR species typing," Malaria Journal, vol. 7, pp. 174-175, 2008.

[79] L. E. Mombo, F. Ntoumi, C. Bisseye et al., "Human genetic polymorphisms and asymptomatic Plasmodium falciparum malaria in Gabonese schoolchildren," The American Journal of Tropical Medicine and Hygiene, vol. 68, no. 2, pp. 186-190, 2003.

[80] M. J. Mackinnon, T. W. Mwangi, R. W. Snow, K. Marsh, and T. N. Williams, "Heritability of malaria in Africa," PLoS Medicine, vol. 2, no. 12, article e340, pp. 1253-1259, 2005.

[81] L. Schofield, J. Villaquiran, A. Ferreira, H. Schellekens, R. Nussenzweig, and V. Nussenzweig, " $\gamma$ Interferon, $\mathrm{CD}^{+} \mathrm{T}$ cells and antibodies required for immunity to malaria sporozoites," Nature, vol. 330, no. 6149, pp. 664-666, 1987.

[82] S. G. S. Vreden, M. F. van den Broek, M. C. Oettinger, J. P. Verhave, J. H. E. T. Meuwissen, and R. W. Sauerwein, "Cytokines inhibit the development of liver schizonts of the malaria parasite plasmodium berghei in vivo," European Journal of Immunology, vol. 22, no. 9, pp. 2271-2275, 1992.

[83] P. D. Crompton, B. Traore, K. Kayentao et al., "Sickle cell trait is associated with a delayed onset of malaria: implications for time-to-event analysis in clinical studies of malaria," Journal of Infectious Diseases, vol. 198, no. 9, pp. 1265-1275, 2008.

[84] N. Gabara, "Developed nations should invest in African universities," BuaNews, 2009.

[85] D. J. Terlouw, M. A. Aidoo, V. Udhayakumar et al., "Increased efficacy of sulfadoxine-pyrimethamine in the treatment of uncomplicated falciparum malaria among children with sickle cell trait in Western Kenya," Journal of Infectious Diseases, vol. 186, no. 11, pp. 1661-1668, 2002. 

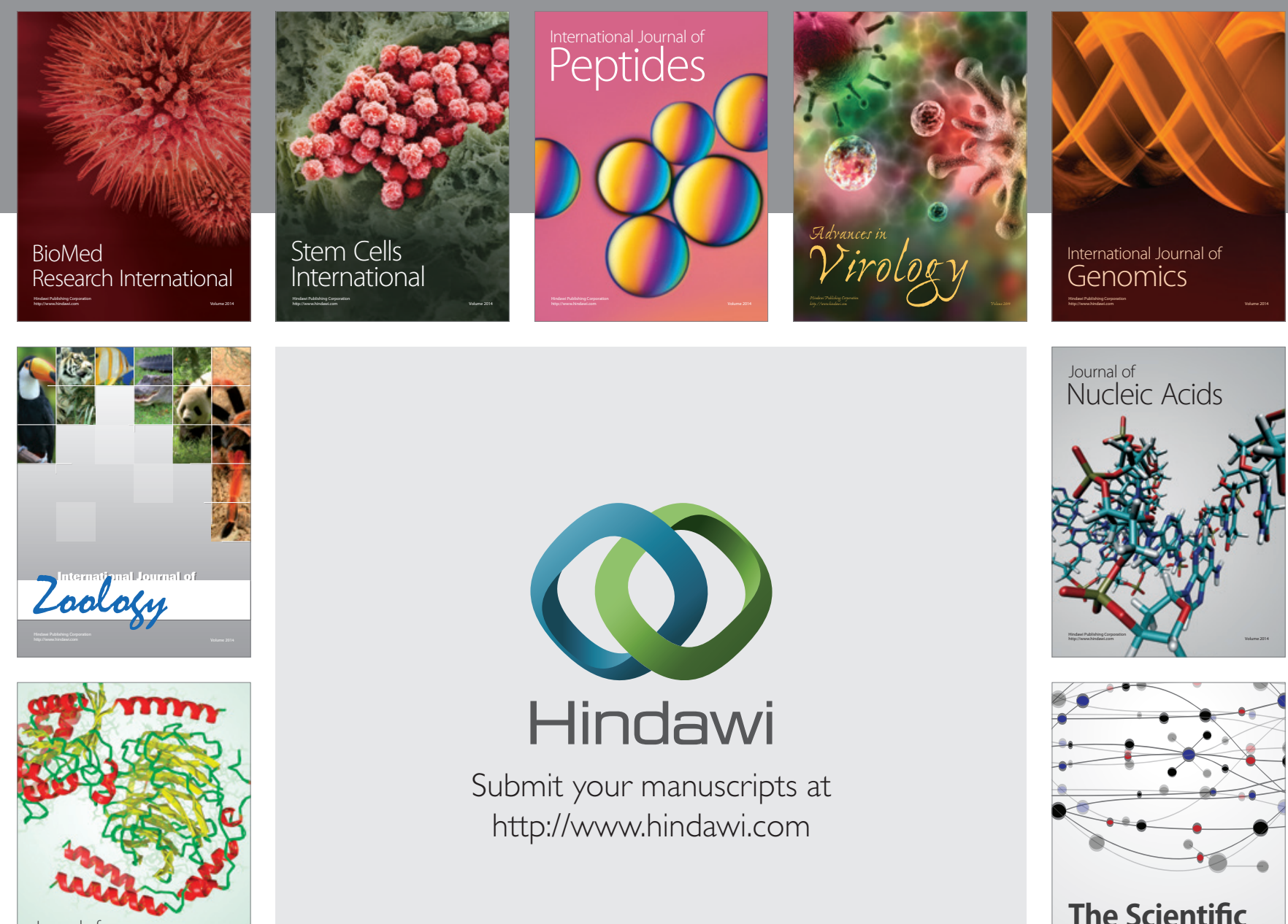

Submit your manuscripts at

http://www.hindawi.com

Journal of
Signal Transduction
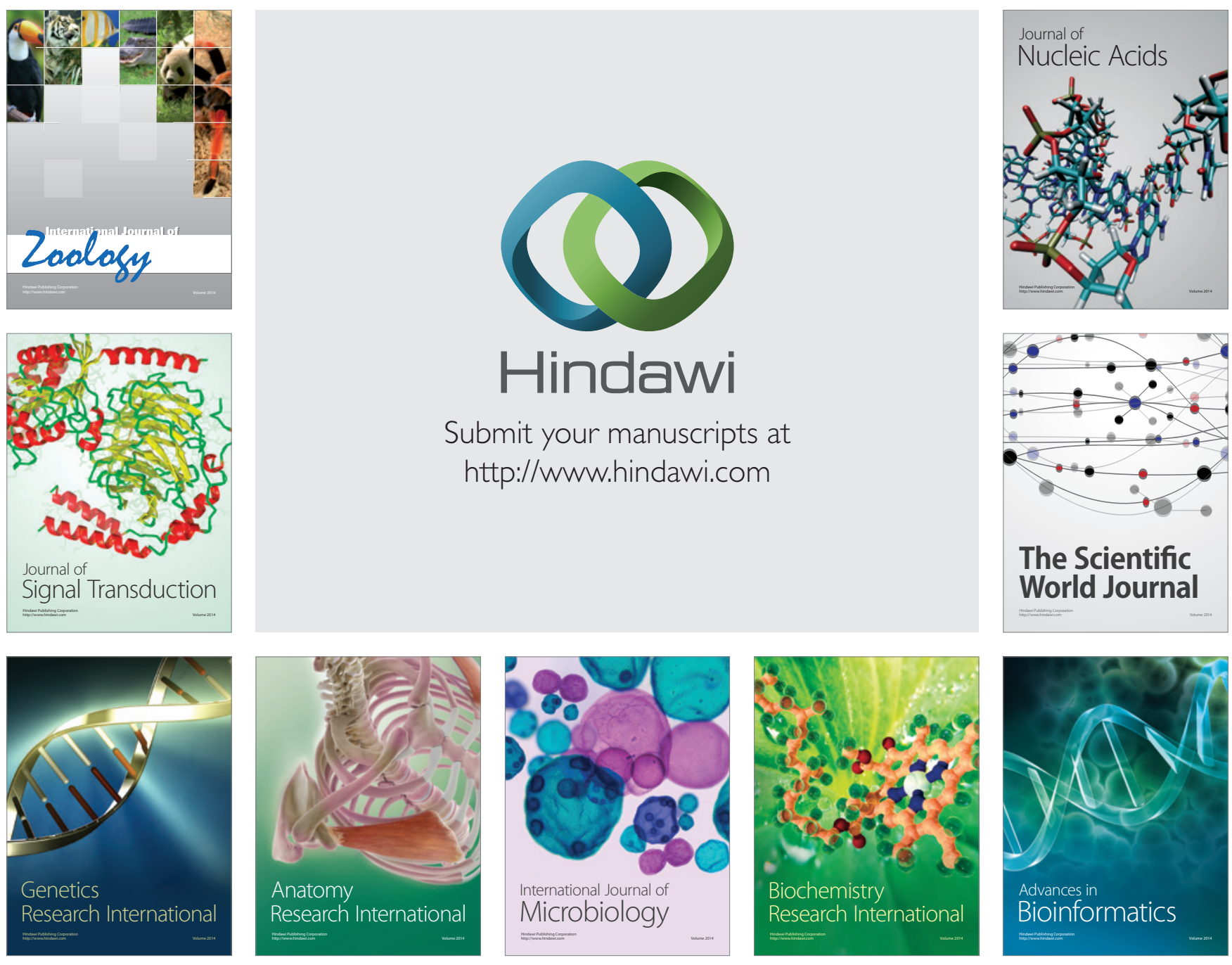

The Scientific World Journal
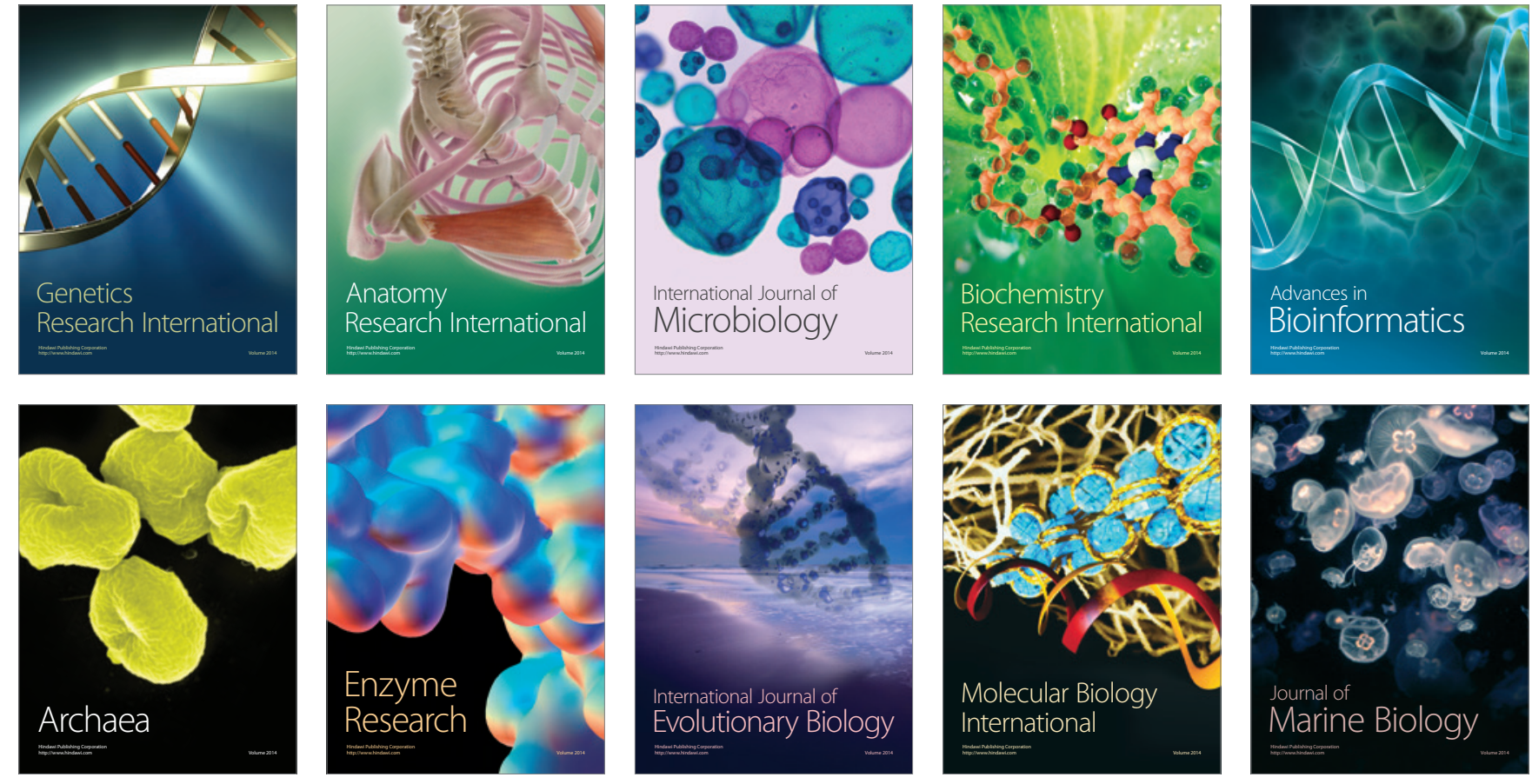